Review

\title{
Emerging Mechanistic Insights into AAA Complexes Regulating Proteasomal Degradation
}

\author{
Friedrich Förster *, Jan M. Schuller, Pia Unverdorben and Antje Aufderheide \\ Department of Molecular Structural Biology, Max-Planck Institute of Biochemistry, \\ Martinsried D-82152, Germany; E-Mails: janschu@biochem.mpg.de (J.M.S.); \\ unverdor@biochem.mpg.de (P.U.); aufderhe@biochem.mpg.de (A.A.)
}

* Author to whom correspondence should be addressed; E-Mail: foerster@biochem.mpg.de; Tel.: +49-89-8578-2632; Fax: +49-89-8578-2641.

Received: 9 May 2014; in revised form: 11 June 2014 / Accepted: 21 July 2014 /

Published: 6 August 2014

\begin{abstract}
The 26S proteasome is an integral element of the ubiquitin-proteasome system (UPS) and, as such, responsible for regulated degradation of proteins in eukaryotic cells. It consists of the core particle, which catalyzes the proteolysis of substrates into small peptides, and the regulatory particle, which ensures specificity for a broad range of substrates. The heart of the regulatory particle is an AAA-ATPase unfoldase, which is surrounded by non-ATPase subunits enabling substrate recognition and processing. Cryo-EM-based studies revealed the molecular architecture of the $26 \mathrm{~S}$ proteasome and its conformational rearrangements, providing insights into substrate recognition, commitment, deubiquitylation and unfolding. The cytosol proteasomal degradation of polyubiquitylated substrates is tuned by various associating cofactors, including deubiquitylating enzymes, ubiquitin ligases, shuttling ubiquitin receptors and the AAA-ATPase Cdc48/p97. Cdc48/p97 and its cofactors function upstream of the $26 \mathrm{~S}$ proteasome, and their modular organization exhibits some striking analogies to the regulatory particle. In archaea PAN, the closest regulatory particle homolog and Cdc48 even have overlapping functions, underscoring their intricate relationship. Here, we review recent insights into the structure and dynamics of the $26 \mathrm{~S}$ proteasome and its associated machinery, as well as our current structural knowledge on the Cdc48/p97 and its cofactors that function in the ubiquitin-proteasome system (UPS).
\end{abstract}

Keywords: AAA-ATPases; 26S proteasome; Cdc48; p97; unfoldase; segregase; cryo-EM 


\section{Introduction}

The ubiquitin-proteasome system (UPS) is responsible for the regulated degradation of proteins in eukaryotic cells [1,2]. Proteins that are to be removed at a specific state of a cell, as well as proteins that do not meet the cellular quality criteria (e.g., folding, glycosylation, integration into their predestined complexes) are labeled with polyubiquitin (poly-Ub) chains by a cascade of E1, E2 and E3 enzymes; ubiquitin ( $\mathrm{Ub}$ ) moieties are attached to lysines of the substrate, which are then ubiquitylated themselves at their lysine residues, giving rise to different types of poly-Ub chains. The $26 \mathrm{~S}$ proteasome degrades the polyubiquitylated substrates into short peptides in an ATP-dependent manner. The UPS is essential in all eukaryotic cells, making it an important drug target for diseases, including cancer [3] and neurodegenerative diseases [4].

Across organisms, the UPS primarily varies most upstream: higher eukaryotes possess a much higher number of E3 Ub ligases (Homo sapiens: >600 [5,6] vs. Saccharomyces cerevisiae 60-100 [7]) and E2 conjugating enzymes (37 vs. 11) that specialize in the ubiquitylation of selected substrates, whereas the downstream machinery is largely identical in all organisms. In particular, the 26S proteasome is functionally and structurally highly conserved [8]. Analogous to prokaryotic ATP-dependent proteases (reviewed in [9]), its central element is a cylindrical core particle (CP), also referred to as the $20 \mathrm{~S}$ proteasome, which is responsible for the proteolytic cleavage of substrates. The CP itself is a rather unspecific protease, and narrow pores at both cylinder ends prevent uncontrolled access of substrates to the active sites in the inner compartment of the CP. Specificity is conferred by the 19S regulatory particle (RP), which binds to one or both cylinder ends of the CP. The RP recruits polyubiquitylated substrates and prepares them for degradation. It consists of a heterohexameric ATPase associated with the diverse cellular activities (AAA) module (subunits Rpt1-6) (reviewed in [10]) and 13 non-ATPases (Rpn1-3, 5-13, 15), which assemble around the AAA-module. The primary functions of the Rpns seem to be substrate recruitment and deubiquitylation of substrates prior to degradation, whereas the AAA-ATPase module exerts the force that is required for substrate unfolding and translocation into the CP. In addition to the Rpts and Rpns, a number of cofactors, commonly referred to as proteasome-interacting proteins (PIPs), is more loosely associated with the $26 \mathrm{~S}$ proteasome, including deubiquitylating enzymes, shuttling Ub receptors and E3 ligases, which all regulate proteasomal function in the cell.

Polyubiquitylation alone by the E1/E2/E3 machinery, however, is often not sufficient for the degradation of substrates by the $26 \mathrm{~S}$ proteasome. This holds in particular for the broad range of substrates targeted by the protein quality control machineries [11]. Another AAA-ATPase complex, called cell division cycle protein $48(\mathrm{Cdc} 48)$ in yeast and p97 in mammals (in the past, also often referred to as VCP), has a central role as a facilitator of proteasomal degradation [12,13]. In conjunction with various cofactors, $\mathrm{Cdc} 48 / \mathrm{p} 97$ promotes poly-Ub chain elongation, segregates substrates from interactors and escorts them to the $26 \mathrm{~S}$ proteasome.

In this review, we focus on recent structural and mechanistic insights into the 26S proteasome and Cdc48, including their associated cofactors. First, we briefly summarize our knowledge on the structure of the $\mathrm{CP}$ and its ATP-dependent regulators in prokaryotes before giving an account of the structure of the eukaryotic RP and the conformational changes that facilitate its function, as well as our current understanding of the major PIPs. We then recapitulate recent information on the Cdc48 machinery and discuss analogies of this machinery to the RP. 


\section{Core Particle}

Archaea possess a CP that is simpler than the eukaryotic CP. Due to the comparably straightforward recombinant expression of the Thermoplasma acidophilum $\mathrm{CP}$, the first atomic structure was solved for this species [14]. The archaeal CP consists of four stacked homoheptameric rings in the order $\alpha \beta \beta \alpha$. Both types of subunits, $\alpha$ and $\beta$, are members of the N-terminal nucleophile hydrolase superfamily, but the $\alpha$-subunits possess an $\mathrm{N}$-terminal extension, rendering them proteolytically inactive. The catalytically active sites are positioned in the cavity formed by the inner $\beta$-subunits, whereas the "antechambers" formed by the $\alpha$ - and $\beta$-subunits are responsible for maintaining substrates in an unfolded state prior to their degradation [15]. The passage through the center of the $\alpha$-ring (the "gate") is regulated by the highly dynamic N-terminal tails of the $\alpha$-subunits, allowing only unfolded substrates to enter [16-19].

While the eukaryotic CP is assembled of heteroheptamers (subunits $\alpha_{1}-\alpha_{7}$ and $\beta_{1}-\beta_{7}$, respectively) instead of homoheptamers, the overall structure of the holocomplex is highly conserved [20]. Of the seven eukaryotic $\beta$-subunits, only $\beta_{1}, \beta_{2}$ and $\beta_{5}$ are catalytically active. The archaeal $\beta$-subunits mostly show chymotrypsin-like peptidase activity, whereas the eukaryotic $\beta_{1}, \beta_{2}$ and $\beta_{5}$ subunits have caspase-, trypsin- and chymotrypsin-like activity, respectively. The active sites can be inhibited by a number of chemical compounds, including the anti-cancer drug bortezomib (reviewed in [21]). In mammals, different orthologs of the three catalytically active subunits have evolved, which are expressed in specific tissues and give rise to "immunoproteasomes" (iCPs) and "thymoproteasomes" (tCPs), in addition to constitutive CPs (reviewed in [22]). The crystal structure of the iCP suggests that stabilization of a proteolytic transition state of $\beta_{5}$ is mostly responsible for the enhanced major histocompatibility complex class I (MHC-I) antigen generation by iCPs [23].

\section{ATP-Dependent Regulators of the Archaeal Core Particle}

Among bacteria, actinomycetes exhibit a UPS-related degradation system based on the prokaryotic Ub-like protein (PUP) [24,25]. More recently, it has become evident that also archaea possess a system similar to the UPS that makes use of small archaeal modifier proteins (SAMPs), which are Ub homologs [26]. Since the archaeal system is more closely related to the UPS, we restrict ourselves to the discussion of this simplified UPS cousin. The Ub-activating E1 enzyme homolog UbaA accomplishes the ligation of SAMP to lysine residues of substrates ("sampylation") [26,27]. The reverse process, desampylation, is achieved by enzymes that are similar to JAB1/MPN/MOV34 (JAMM) deubiquitylating enzymes (DUBs) [28]. DUBs of this class, including Rpn11, possess an Mpr1-Pad1 N-terminal (MPN) domain with a characteristic JAMM motif that gives rise to metalloprotease activity [29].

Many archaeal organisms have a gene that codes for the proteasome activating nucleotidase (PAN), which has high sequence similarity to the Rpts and forms homohexamers [30]. Indeed, molecular studies have shown that PAN promotes degradation of small peptides by the $\mathrm{CP}$ in a similar manner as the RP does, and it forms complexes with the CP that get stabilized in the presence of ATP- $\gamma \mathrm{S}$ [31]. PAN's role as a homolog of the proteasomal proteases is also underscored by the structures of PAN fragments, which are highly similar to their eukaryotic counterparts [32,33]; similar to the Rpts, PAN assembles to a trimer of dimers with $\mathrm{N}$-terminal coiled coil dimers protruding from the pseudo six-fold 
symmetrical oligosaccharide binding fold $(\mathrm{OB})$ ring, which resides on top of a ring formed by the AAA-domains (AAA-ring).

Pivotal for the binding of PAN to the $\mathrm{CP}$ is a $\mathrm{C}$-terminal motif comprising a hydrophobic residue $(\mathrm{Hb})$ and a tyrosine followed by a residue of any type (HbYX) [34]. Cryo-EM studies of small HbYX containing peptides bound to the $\mathrm{CP}$ revealed that these motifs insert into pockets at the interfaces of the $\alpha$-subunits and trigger substantial conformational changes of the CP [35]. The precise binding mode of the C-terminal peptides is still under debate, because the crystal structures of chimeric constructs yielded inconsistent results [36,37]. Among the Rpts, only Rpt2, Rpt3 and Rpt5 exhibit the HbYX motif at their C-termini [34]. These subunits bind to the $\mathrm{CP}$ in a similar manner as observed for isolated peptides, although the conformational changes of the CP were not seen in the holocomplex [38-40]. The reason for this discrepancy may be that the addition of isolated HbYX peptides results in the occupancy of all CP binding sites, whereas only a fraction of pockets is engaged in the CP-AAA-ATPase complexes, due to the symmetry mismatch of CP and the AAA-ATPase module (pseudo-six-fold vs. pseudo-seven-fold). The accordingly more dynamic binding of the C-termini [41] likely results in more subtle effects on the free energy landscape of the CP gate that may, for example, enable easier gate opening upon peptide translocation.

For a long time, it has been puzzling that some archaea, like T. acidophilum, do not have a PAN gene, whereas the CP is strictly conserved [42]. Among the archaeal AAA-ATPases, Cdc48 homologs, originally coined VCP-like ATPase of Thermoplasma acidophilum (VAT) [43], and a group of proteins only found in Archaeoglobus and methanogenic archaea (AMA) also exhibit the C-terminal HbYX motif [44]. Thus, early on, both proteins were genuine candidates for CP regulators. However, it has only been shown recently that Cdc48 and AMA proteins can also bind the CP [45-47]. These studies all required stabilizing the CP-AAA-ATPase interaction using an ATPase mutation or cysteine cross-linking. Accordingly, PAN, Cdc48 and AMA proteins seem to have overlapping functions in archaea.

\section{Molecular Architecture of the 19S Regulatory Particle}

The RP comprises two independently assembling sub-complexes, the base and the lid [48]. The base consists of the Rpts, Rpn1, Rpn2 and Rpn13, whereas the lid comprises the remaining Rpns with the exception of Rpn10, which is apparently associated only after the base and the lid form the RP. The Rpts are arranged into a ring of the order Rpt1/2/6/3/4/5 [49,50], which adopts a specific register on the $\mathrm{CP}$, as determined by protein interaction studies and chemical cross-linking [49,41,51]. However, due to the symmetry mismatch between the ATPase module and CP, the binding between both complexes is not tight and allows for considerable lateral motion of the AAA-ATPase hexamer on the CP (see below). Rpn1 and Rpn2, the two largest, evolutionarily-related Rpns, bind to the tips of the coiled coil dimers of Rpt1/2 and Rpt3/6, respectively [38-40,52]. Whereas Rpn1 is positioned as somewhat isolated in the $26 \mathrm{~S}$ holocomplex, reflecting its role as a docking platform for many PIPs, Rpn2 is tightly integrated with the lid, and the Ub receptor Rpn13 is positioned near the N-terminus of Rpn2 in the very periphery of the $26 \mathrm{~S}$ holocomplex [53].

The lid subunits, Rpn9, 5, 6, 7, 3 and 12, share a similar architecture; their hallmarks are proteasome-COP9-initiation factor 3 (PCI) modules, which assemble into a heterohexameric 
horseshoe $[39,40,54]$. This horseshoe flanks the AAA-ATPase module and directly binds to the CP via Rpn6 and Rpn5, stabilizing the 26S proteasome during conformational switching [52]. The smallest Rpn, Rpn15 (also called Sem1 in yeast and Dss1 in mammals), stabilizes the horseshoe between Rpn7 and Rpn3 [55,56]. The C-termini of the PCI subunits together with those of the MPN domain-containing subunits, Rpn8 and Rpn11, assemble into a helical bundle, which tethers the lid together [38,57]. Rpn8 and Rpn11 dimerize through their MPN domains [38,58,59]. The JAMM motif is absent in Rpn8, rendering this subunit catalytically inactive. In the $26 \mathrm{~S}$ holocomplex, the DUB Rpn11 is positioned directly above the central pore of the ATPase module, enabling it to remove the poly-Ub chain from the substrate immediately prior to degradation; i.e., proteolytic cleavage occurs between the ubiquitylated lysine of the substrate and the poly-Ub molecule [60,61]. For a more detailed review of the RP architecture, we refer to [62].

\section{Conformational Switching of the 26S Proteasome}

In all initial high-resolution cryo-EM studies, the $26 \mathrm{~S}$ proteasome was imaged in the presence of ATP and in the absence of substrate $[38,40,51,63,64]$. Although, under these conditions, the AAA-ATPase subunits may continuously exchange nucleotides, relatively well-defined structures were obtained, indicating that the particles were predominantly in a single conformation. A hallmark of the AAA-ATPase configuration in this predominant low-energy state is a staircase- or lock washer-like arrangement of the AAA-domains [39], similar to that observed in V-ATPases [65], RecA/DnaB-type helicases [66] and AAA-type helicases [67].

Different approaches to stabilize alternative $26 \mathrm{~S}$ conformations were the alteration of the free energy landscape by replacing ATP by ATP- $\gamma \mathrm{S}$ in the buffer [68] and the addition of polyubiquitylated substrate to proteasomes with dysfunctional Rpn11 [69]. Somewhat surprisingly, both approaches revealed essentially the same conformational change: the AAA-ATPase hexamer undergoes a dramatic rearrangement concomitant with a $\sim 20^{\circ}$ rotation of the non-ATPases. In-depth classification of $26 \mathrm{~S}$ proteasome particles in the presence of ATP and ATP $-\gamma \mathrm{S}$ revealed a third conformational state, which is intermediate between the presumable low- and high-energy states [52]; the AAA-ATPase module essentially remains in the low-energy conformation, whereas the non-ATPases are positioned similar as in the high-energy state. These three states could facilitate the degradation of polyubiquitylated substrates in the following manner (Figure 1): Substrates primarily associate with the $26 \mathrm{~S}$ proteasome when it adopts its low-energy conformation. In this state, substrate binding is still reversible, and proteasome-associated DUBs may process the poly-Ub chain (reviewed in [70]). Conformational switching to the intermediate conformation, possibly facilitated by different nucleotide loading of one site, may transfer the substrate to the mouth of the OB ring, committing the substrate to degradation [71-73]. In both, the intermediate and the high-energy state, the conformation of Rpn11 and its local environment seem to be essentially identical. The DUB is presumably active in these two states in contrast to the low-energy state; a composite active site may be formed by Rpn11, the AAA-ATPase hexamer and Rpn2 [58]. Cleavage of the poly-Ub chain may thus occur in both states. The high-energy state then enables unfolding and translocation of the substrate into the CP by releasing its energy, probably in rapid bursts, as seen for bacterial ATP-dependent proteases [74,75]. 
Figure 1. Conformational states of the $26 \mathrm{~S}$ proteasome. (Top row) The $S$. cerevisiae $26 \mathrm{~S}$ proteasome has been imaged in three distinct conformational states using cryo-EM single particle analysis [52]. The EM densities are segmented according to their main functional modules indicated in the legend. Upon transition from the low-energy conformation (left) to the intermediate conformation (center), the non-ATPases rotate en bloc by approximately $25^{\circ}$, and the ATPase module shifts by approximately $5 \AA$. The ATPases undergo a large-scale conformational change during the transition of the $26 \mathrm{~S}$ proteasome from the intermediate to the high-energy conformation (right) concomitant with a shift of the non-ATPases. The hypothesized functions of the states are substrate recruitment (low-energy), substrate commitment (intermediate) and substrate translocation into the core particle ( $\mathrm{CP}$, high-energy). (Bottom row) Among the three states, the local environment of Rpn11 is essentially identical in the intermediate and translocating state, suggesting that the enzyme is active in both states.

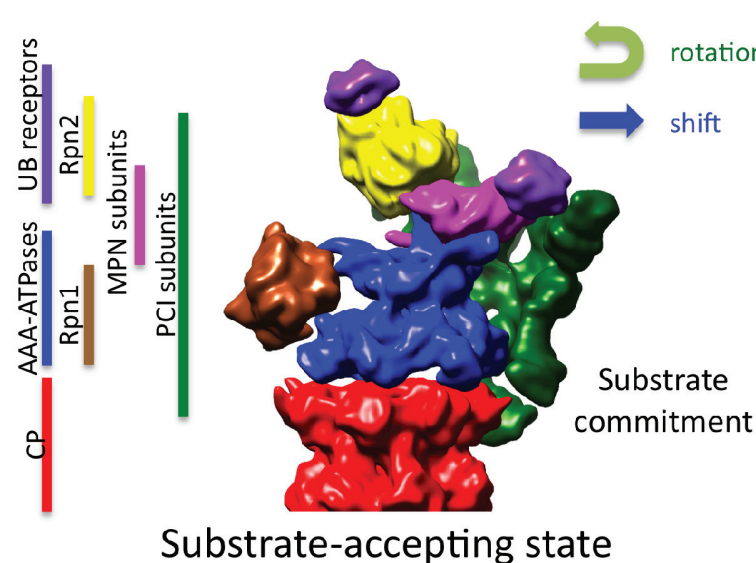

Substrate-accepting state

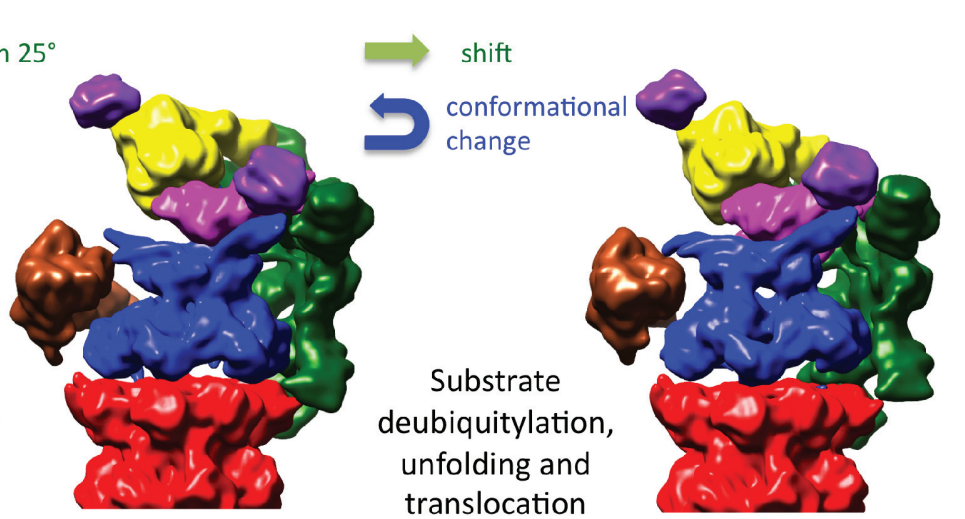

Intermediate state

Translocating state
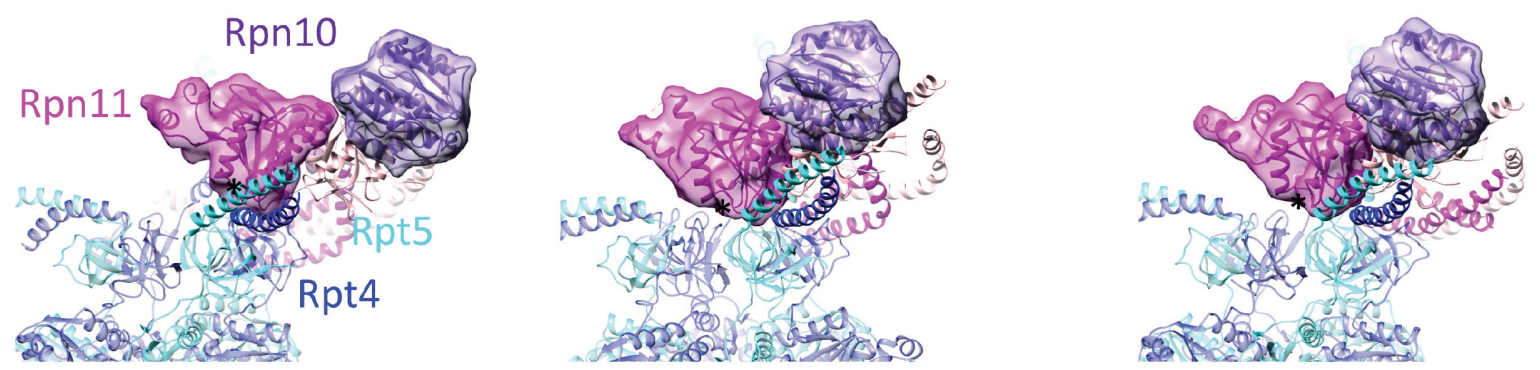

6. Regulation of Proteasomal Degradation by Proteasome-Interacting Proteins

In the crowded environment of the cell, many PIPs bind to the $26 \mathrm{~S}$ proteasome, which largely dissociate during the typical biochemical purification procedures of the $26 \mathrm{~S}$ proteasomes, due to the dynamical nature of these interactions [76,77]. Three major groups are most abundant among PIPs that all modulate proteasome activity by different means (reviewed in [7,8]): (i) the "shuttling" Ub receptors, Rad23 (HR23a/b in mammals), Dsk2 (PLIC-1) and Ddi1, mediate the binding of ubiquitylated substrates to the proteasome [78-81]; (ii) DUBs trim Ub chains and may prevent them from degradation (reviewed in [70]) (the Ub C-terminal hydrolase, Uch37 (also referred to as UchL5 in mammals), and the Ub-specific protease, Ubp6 (Usp14), are the most abundant proteasome-associated DUBs); (iii) E3 Ub ligases, in particular the subclass of E4 ligases that specializes in extending 
existing Ub chains, antagonize DUB function and couple ubiquitylation to degradation when binding to the 26S proteasome. Nine Ub ligases have been proposed to interact with the proteasome (reviewed in [82]), of which the E4 enzyme, HECT Ub ligase 5 (Hul5, UBE3B/C in mammals), is the most abundant one in $26 \mathrm{~S}$ proteasome purifications [83].

All currently established PIP associations involve Rpn1 and Rpn2 (Figure 2; for comprehensive reviews, we refer to $[7,8,82,84]$ ), and it has been suggested that these subunits coordinate PIP occupancy [85]. Essentially, all PIPs that are currently known to associate with Rpn1, including the shuttling Ub receptors and Ubp6, possess Ub-like (UBL) domains. S. cerevisiae Rad23, Dsk2 and Ddil all have been reported to bind to the toroid-shaped leucine-rich repeat (LRR) domain of Rpn1 via their UBL domains in a partially competitive manner (Figure 3) [81,86,87], whereas, in higher eukaryotes, they additionally bind to Ub receptors, in particular the Ub-interacting motifs of Rpn10 [88,89]. Likewise, Ubp6 associates with Rpn1 primarily via its UBL domain [83], albeit in vitro studies suggest that also other protein segments may contribute to the interaction [85]. A hallmark of Ubp6 is its activation upon binding to the $26 \mathrm{~S}$ proteasome [83]. Vice versa, Ubp6 also influences proteasome activity: binding of Ub-conjugates and Ub-aldehyde to proteasome-bound Ubp6 accelerates degradation of short peptides [90], while Ubp6 delays proteasomal degradation of polyubiquitylated substrates independent of the Ubp6 isopeptidase activity $[4,91]$.

Figure 2. The most abundant cofactors of $26 \mathrm{~S}$ proteasome and Cdc48 involved in the ubiquitin-proteasome system (UPS). (A) Proteasome-interacting proteins (PIPs). The DUB Ubp6 and all shuttling Ub receptors (sUbR), Rad23, Dsk2 and Ddi1, bind to Rpn1 via their UBL domains, whereas the E4-ligase Hul5 interacts with Rpn2. In higher eukaryotes, an additional DUB, UCH37, binds to the Ub receptor Rpn13. (B) In Cdc48, the majority of cofactors, including the heterodimeric Npl4-Ufd1 substrate recruiting cofactor and the DUB Out1, bind to the N-domain. Contrarily, the E4 Ligase, Ufd2, and the Ub-chain release factor, Ufd3, bind to the unstructured C-terminal tail. Additionally, the shuttling substrate receptors (sUbR), Rad23 and Dsk2, are associated via Ufd2.

A

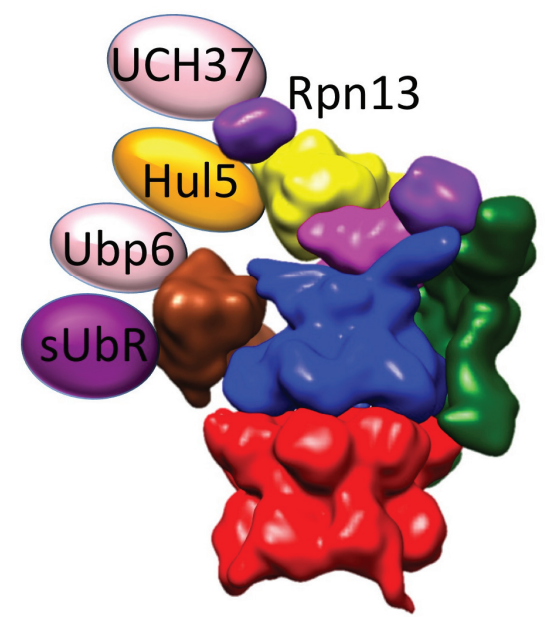

B

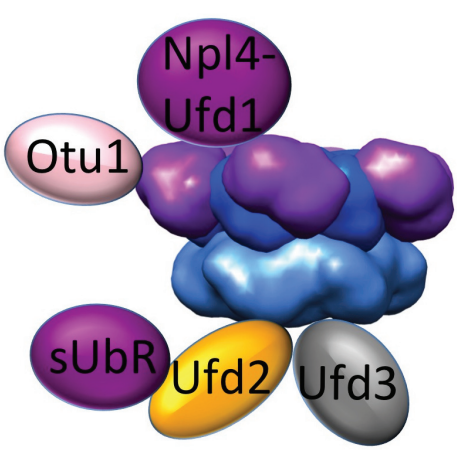


Figure 3. Schematic representation of sequences of PIPs and the major Cdc48-associated cofactors involved in the UPS. PIPs bind to the docking platforms, Rpn1 and Rpn2, all Cdc48-associated proteins to either the $\mathrm{Cdc} 48 \mathrm{~N}$-domain or the $\mathrm{C}$-terminal tail (C). Yellow: domains with an Ub-related fold; purple: domains that bind to Ub and Ub-related domains (UBD); pink: DUB domains; orange: ubiquitin ligase domains; red: domains involved in PIP or Cdc48-cofactor association; blue: AAA-domain; gray: established domains with different or unknown functions. The following additional abbreviations are introduced: TPR: tetratricopeptide repeat; $\beta$-sw: $\beta$-sandwich domain; $9 \alpha \mathrm{H}$ : alpha helical bundle; RVP: retroviral protease-like domain; XPCB: xeroderma pigmentosum group $\mathrm{C}$ protein-like domain; USP: ubiquitin-specific protease domain; B: BS1; ARM: armadillo-repeat containing domain; U: RING-like U-box domain; Z: Zn-finger motif; WD40: WD40-repeat containing domain; P: PLAA family ubiquitin binding (PFU) domain.

$26 S$

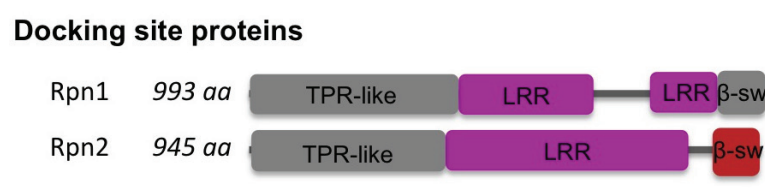

Shuttling Ub Receptors

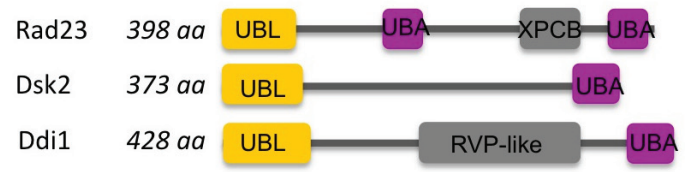

Substrates recruiting cofactors

Rpn13 156 aa

hRpn13 407 aa

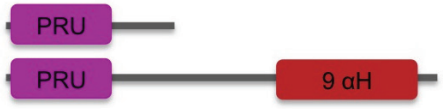

E4 Ub ligases

Hul5 910 aa

DUBs

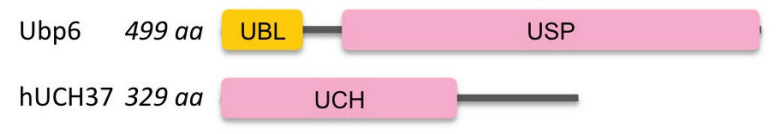

Cdc48

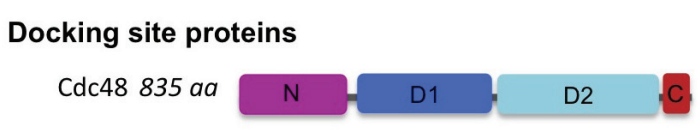

Shuttling Ub Receptors

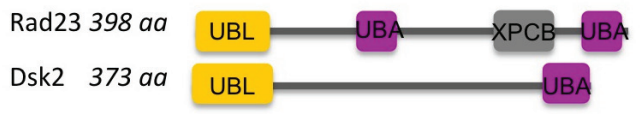

Substrates recruiting cofactors

Npl4 580 aa UBX

Ufd1 361 aa $\quad$ UT3

E4 Ub ligases

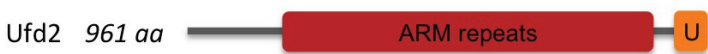

DUBs

Otu1 301 aa

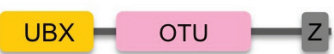

Other

Ufd3 $715 a a$

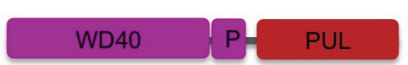

\begin{tabular}{|c|c|c|c|c|c|c|c|}
\hline & & & & & & Prot. $>600$ aa & Prot. $<600$ aa \\
\hline Ub & UBD & DUB & ligase & association & other & 100 aа & 200 aа \\
\hline
\end{tabular}

The Ub receptor Rpn13, also referred to as Adrm1 in mammals, binds to the C-terminal domain of Rpn2 essentially in a stoichiometric ratio in S. cerevisiae (Figure 3) [39,53]. However, this "canonical" subunit binds dynamically in higher eukaryotes [76] and is typically found in substoichiometric amounts in $26 \mathrm{~S}$ proteasome preparations [50,92]. Thus, Rpn13 might also be viewed as an Rpn2-associated PIP. Higher eukaryotes express an additional DUB, UCH37, which binds to a domain of Rpn13 that is only found in organisms with an UCH37 gene [92-97]. Furthermore, the E3/E4 ligase Hul5 avidly interacts with Rpn2 [98]. Hul5 and Ubp6 are suggested to be antagonists and cooperatively 
enable $\mathrm{Ub}$ chain remodeling [98]. The $26 \mathrm{~S}$ proteasome structure would indeed allow binding of Ubp6 and Hul5 to Rpn1 and Rpn2, respectively, such that the proteins are positioned in mutual proximity (Figure 2). An additional function of proteasome-associated E2 and E3/E4 enzymes, as well as DUBs seems to be the (de)-ubiquitylation of $26 \mathrm{~S}$ proteasome subunits regulating proteasomal activity [77]. The in situ arrangement of PIPs is a largely uncharted territory at this point. Further structural characterization will be essential for mechanistic understanding of their contribution to proteasomal regulation.

\section{Cdc48/p97—A Facilitator of Proteasomal Degradation}

Polyubiquitylation by the E1/E2/E3 machinery is not sufficient for proteasomal degradation of many substrates. The AAA-ATPase homohexamer cell division control protein 48 (Cdc48), commonly referred to as p97 and historically also as VCP in mammals, is a key facilitator of proteasomal degradation of many polyubiquitylated substrates in the cell. In particular, this protein complex is required for the extremely broad range of substrates that is degraded by different cellular quality control pathways: Cdc48 is a hallmark component of endoplasmic reticulum-associated degradation (ERAD) [99-101], mitochondria-associated degradation (MAD) [102] and cytosolic ribosomal protein quality control (RQC) [103]. Moreover, Cdc48 is centrally involved in the tightly controlled chromatin-associated degradation [104] and the engineered Ub fusion degradation pathway (UFD) [105], which proved a useful model system for studying many aspects of Cdc48 in proteasomal degradation. Of note, Cdc48 is not strictly required for the degradation of all substrates of these pathways, as shown, for example, for specific ERAD substrates, for which the proteasomal AAA-ATPases are sufficient for degradation [106-108]. In addition to its functions in the UPS, Cdc48 is also involved in other Ub-mediated degradation pathways, for which we refer to [12].

In contrast to proteasome-associated AAA-ATPases, the major enzymatic function of eukaryotic Cdc48 does not seem to be that of an unfoldase; its main catalytic function is rather that of a "segregase". Cdc48 segregates ubiquitylated substrates from non-modified partners [109]. These unmodified interactors may be other subunits of a complex if the substrate is part of an assembly, a tightly associated E3 ligase or an organelle membrane. Various cofactors associate with Cdc48 to recruit specific substrates and process them further for degradation. These cofactors tend to be organized in a hierarchical manner and confer specificity to Cdc48 [12]. Here, we only discuss the best-studied examples acting in the UPS (Figures 3 and 4).

Recruitment of the heterodimeric Ub acceptor Npl4-Ufd1 allows Cdc48 to bind to polyubiquitylated substrates [110,111]. Cdc48-associated E4 enzymes, including the RING-related ligase Ufd2 (E4B in mammals), facilitate poly-Ub chain elongation [112]. Similar to the proteasome-associated E4 ligases, the function of Cdc48-associated $\mathrm{Ub}$ ligases may be antagonized by Cdc48-associated DUBs, including the ovarian tumor protease Otu1 (YOD1 in mammals) [113], and by Ufd3. The shuttling Ub receptors Rad23 and Dsk2, bind to Ufd2 (PLAA in mammals) [114], enabling substrate targeting to the 26S proteasome (Figure 4). Thus, the functions of PIPs and Cdc48-interacting cofactors appear analogous [115]. 
Figure 4. Cdc48-centered escort function for substrates of the UPS. An enzymatic cascade of Ub-activating enzyme (E1), Ub-conjugating enzyme (E2) and Ub ligase (E3) covalently links Ub moieties (yellow) to lysine residues of a protein that is targeted by the UPS. Via the Ub binding Npl4-Ufd1 complex (purple), Cdc48 (cyan) recruits the substrate. The ATP-dependent segregase activity of Cdc48 liberates the substrate from its non-ubiquitylated interaction partners. The fate of the substrate is then determined by Cdc48-associated $\mathrm{Ub}$ chain-remodeling cofactors. While the DUB Otul and Ufd3 may prolong the lifetime of the substrate by deubiquitylation and substrate release, respectively, the E4 enzyme Ufd2 (orange) extends the poly-Ub chain and facilitates the transfer of the substrate to the $26 \mathrm{~S}$ proteasome by the shuttling Ub receptors Rad23 and Dsk2 (dark purple).
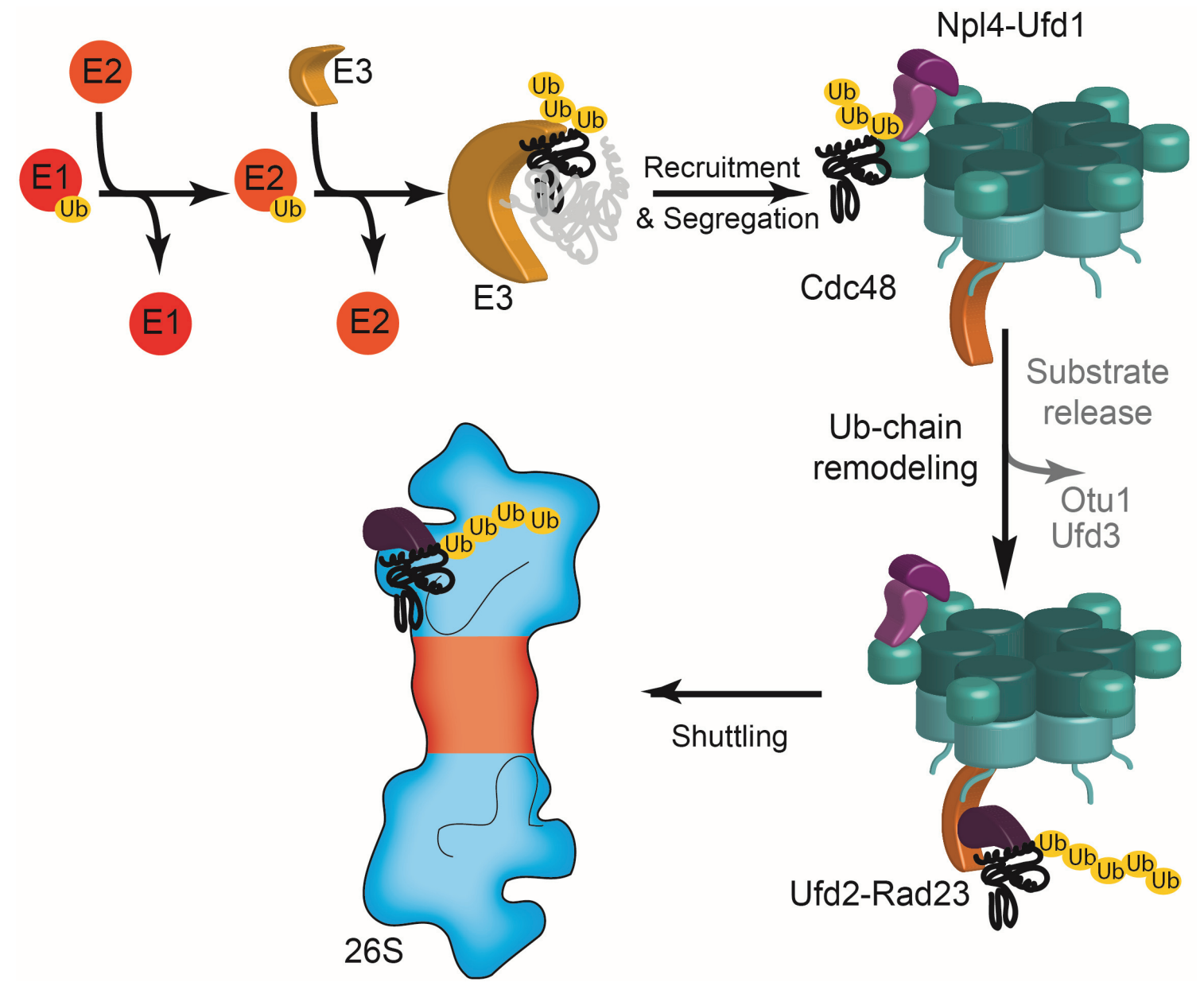

\section{Structure of Cdc48 and Its Associated Machinery}

Like the proteasomal AAA-ATPase module and PAN, Cdc48 consists of an N-terminal (N) domain and two ring-forming domains, D1 and D2 (Figure 4). However, in the case of Cdc48, both D1 and D2 are AAA-domains, whereas the rings of the proteasomal ATPases are formed by an OB-domain and an AAA-domain. The structure of the p97 homohexamer has been studied by X-ray crystallography revealing two stacked AAA-rings in head-to-tail orientation and the N-domain tightly-associated with the outer surface of the D1 domain [116,117]. A striking feature of the crystallographic structure is the narrow central pore of the D1 AAA-ring, which is occluded by a pronounced density, possibly a $\mathrm{Zn}$ ion. Consistent with this observation, eukaryotic $\mathrm{Cdc} 48$, in contrast to its archaeal homologs, lacks critical 
aromatic residues in the D1 pore that are required for unfoldase activity in ATP-dependent proteases [118]. Thus, the structure and composition of the D1 ring suggest that eukaryotic Cdc48 does not thread substrates through its central channel, in contrast to the proteasomal AAA-ATPases. Consistent with these observations, eukaryotic $\mathrm{Cdc} 48$ does not promote the degradation of folded model substrates by the CP, in contrast to its archaeal counterpart [119]. Interestingly, substitution of the eukaryotic D1 pore loop by the archaeal version restores the unfoldase activity of the eukaryotic Cdc 48 and according degradation of substrates by the CP $[118,119]$. Moreover, eukaryotic wild-type Cdc48 promotes the degradation of short peptides, hinting at regulatory function activity [119]. However, this effect is much more pronounced for the archaeal $\mathrm{CP}$ than for eukaryotic $\mathrm{CP}$, and it remains to be seen whether the regulatory activity of eukaryotic Cdc48 observed in vitro is of physiological importance.

Compared to the lock washer-like quaternary structures of the proteasomal ATPase module, the X-ray crystallographic structures of p97 appear essentially six-fold symmetrical. However, the quaternary structures observed in the crystals are likely to be unphysiological, because they may be induced by packing forces, which are in a similar range as those generated during the nucleotide cycle [117]. For example, the radii of gyration obtained from small-angle X-ray scattering [120] exceed those obtained from the crystal structures for many nucleotide states. Hence, structural insights into the structural rearrangements of $\mathrm{Cdc} 48$ during its nucleotide cycle remain on a low-resolution level to date. All nucleotide-binding sites of the D1 ring are occupied with ADP under physiological conditions [121,122], suggesting that the D1 ring functions as a rigid scaffold analogous to the OB-ring of the proteasomal AAA-ATPase module. In contrast, nucleotide binding to D2 is dynamic, with a maximum load of 3-4 nucleotides [121], again similar to CP-associated proteases [9,123]. Upon ATP binding, the D1 and D2 rings rotate with respect to each other by approximately $20^{\circ}$ [124-126].

The substrate-recruiting cofactors confer specificity and modulate affinities for substrate-processing cofactors, but may also influence the ATPase activity of Cdc48 [127]. To our current knowledge, substrate-recruiting cofactors primarily dock to the N-domain [12]. This domain adopts a pseudo-symmetrical double-psi-beta barrel fold [128,129]. Cofactors bind to the N-domain via Ub regulatory $\mathrm{X}(\mathrm{UBX})$ and UBX-like domains, as well as different linear sequence motifs, including the binding site 1 (BS1) and VCP binding (VBM) motifs, often in a competitive manner (reviewed in [130]). The most important substrate-recruiting cofactors, the heterodimeric Np14-Ufd1 complex and Shp1 (p47 in mammals), which mediates non-proteasomal degradation, bind mutually exclusively to the N-domain.

Both subunits of the Np14-Ufd1 complex bind to the Cdc48 N-domain, although probably those of neighboring Cdc48 subunits in the holocomplex. The N-terminal Ufd1 truncation 3 domain (UT3) and the Cdc48 N-domain share the same architecture [131,132], whereas the C-terminal domain of Ufd1 is unstructured in isolation and recruited to Cdc48 by its BS1 motif [133]. Both, the Cdc48 and Ufd1 $\mathrm{N}$-domains bind mono- and poly-Ub, suggesting that doubling these domains in a complex is a means of increasing the affinity for ubiquitylated substrates [132]. Np14 comprises three domains. It binds to the Cdc48 N-domain via its N-terminal UBX-like domain [134]. The central domain of Npl4 is the JAMM-deficient MPN domain, which, analogous to the catalytically inactive MPN domain of Rpn8, has not been assigned to a function at this point. The C-terminal Npl4 zinc finger (NZF) domain, which is only present in higher eukaryotes, binds weakly to free Ub, suggesting that this domain further increases affinity to substrates [135]. Low-resolution cryo-EM data of the glutaraldehyde 
cross-linked ternary p97-Np14-Ufd1 complex indicate that one Np14-Ufd1 heterodimer binds per p97 homohexamer. The holocomplex co-exists in multiple conformations, probably induced by large-scale repositioning of the $\mathrm{N}$-domain dependent on the respective nucleotide state [136].

A major substrate-processing cofactor involved in the UPS is the E4 enzyme Ufd2, which was the first member of this type of Ub ligases specialized for the efficient extension of ubiquitylation nuclei to be identified [137-139]. In yeast, Ufd2 binds to the very C-terminus of Cdc48, whereas its mammalian homolog binds to the N-domain via its VBM [137,140]. Ufd2 is antagonized by Ufd3, which binds to the Cdc48 C-terminus through its C-terminal armadillo repeat domain [141,142]. The antagonizing function of Ufd3 is thought to be due to mutually exclusive binding with Ufd 2 and/or due to the induction of the release of monoubiquitylated substrates. The DUB Otu1 can bind simultaneously with Ufd3 to Cdc48. It shortens poly-Ub chains and may hence preserve substrate from eventual degradation [113]. Otu1 binds to Cdc48 via its UBX domain that associates with two N-domains, as suggested by X-ray crystallographic analysis [143]. In contrast to proteasome-associated DUBs, Otul does not require Cdc48 association for its catalytic activity [113]. The shuttling Ub receptors $\operatorname{Rad} 23$ and Dsk2 associate with both $26 \mathrm{~S}$ proteasome and Cdc48 via Ufd2, enabling the delivery of substrates for degradation. The N-terminal UBL-interacting domain of Ufd2 specifically interacts with high affinity with the UBL domains of Rad23 and Dsk2, but not Ddi1 [114]. This eight-helix domain binds the Rad23 and Dsk2 UBL domains distinct from the modes of interactions seen for Ub-receptors, like Rpn10, Rpn13 and the UBA domains of the shuttling Ub receptors, highlighting the large variation of $\mathrm{Ub}$ and UBL binding domains [114]. In summary, the Cdc48 cofactors described here are part of a Cdc48-centered 'escort function' for substrates to the 26S proteasome (Figure 4) [112].

\section{Conclusions}

In recent years, structural and functional studies have yielded substantial progress in our mechanistic understanding of proteasomal degradation. In particular, cryo-EM studies have provided us with detailed pictures of the $26 \mathrm{~S}$ proteasome in its different conformational states, based on which the working hypotheses for the mechanism of degradation could be formulated, which need to be tested now. The forthcoming challenges will be structural studies on the regulation of the $26 \mathrm{~S}$ by the dynamically-associated PIPs and, eventually, its coordination with Cdc48 and its various cofactors. With the advent of the UPS, Cdc48 seems to have evolved from an AAA-type unfoldase in archaea into a segregase in eukaryotes and acquired a large set of cofactors for substrate recruitment and processing. The large conformational variability of AAA-ATPases makes structural studies of Cdc48 and its cofactors challenging, but such experiments will undoubtedly provide exciting insights into the evolution of this enzyme and the UPS in general.

\section{Acknowledgments}

This work was supported by the Deutsche Forschungsgemeinschaft/GRK1721.

\section{Author Contributions}

All authors wrote the text. 


\section{Conflicts of Interest}

The authors declare no conflict of interest.

\section{References}

1. Hershko, A.; Ciechanover, A. The ubiquitin system. Annu. Rev. Biochem. 1998, 67, 425-479.

2. Hershko, A.; Ciechanover, A.; Varshavsky, A. Basic medical research award. The ubiquitin system. Nat. Med. 2000, 6, 1073-1081.

3. Hoeller, D.; Dikic, I. Targeting the ubiquitin system in cancer therapy. Nature 2009, 458, 438-444.

4. Lee, B.H.; Lee, M.J.; Park, S.; Oh, D.C.; Elsasser, S.; Chen, P.C.; Gartner, C.; Dimova, N.; Hanna, J.; Gygi, S.P.; et al. Enhancement of proteasome activity by a small-molecule inhibitor of USP14. Nature 2010, 467, 179-184.

5. Deshaies, R.J.; Joazeiro, C.A. Ring domain E3 ubiquitin ligases. Annu. Rev. Biochem. 2009, 78, 399-434.

6. Komander, D. The emerging complexity of protein ubiquitination. Biochem. Soc. Trans. 2009, 37, 937-953.

7. Finley, D.; Ulrich, H.D.; Sommer, T.; Kaiser, P. The ubiquitin-proteasome system of saccharomyces cerevisiae. Genetics 2012, 192, 319-360.

8. Finley, D. Recognition and processing of ubiquitin-protein conjugates by the proteasome. Annu. Rev. Biochem. 2009, 78, 477-513.

9. Sauer, R.T.; Baker, T.A. AAA+ proteases: ATP-fueled machines of protein destruction. Annu. Rev. Biochem. 2011, 80, 587-612.

10. Bar-Nun, S.; Glickman, M.H. Proteasomal AAA-ATPases: Structure and function. Biochim. Biophys. Acta 2011, 1, 67-82.

11. Buchberger, A.; Bukau, B.; Sommer, T. Protein quality control in the cytosol and the endoplasmic reticulum: Brothers in arms. Mol. Cell 2010, 40, 238-252.

12. Buchberger, A. Roles of Cdc48 in regulated protein degradation in yeast. Subcell Biochem. 2013, 66, 195-222.

13. Franz, A.; Ackermann, L.; Hoppe, T. Create and preserve: Proteostasis in development and aging is governed by Cdc48/p97/VCP. Biochim. Biophys. Acta 2014, 1843, 205-215.

14. Lowe, J.; Stock, D.; Jap, B.; Zwickl, P.; Baumeister, W.; Huber, R. Crystal structure of the 20S proteasome from the archaeon T. Acidophilum at 3.4 A resolution. Science 1995, 268, 533-539.

15. Ruschak, A.M.; Religa, T.L.; Breuer, S.; Witt, S.; Kay, L.E. The proteasome antechamber maintains substrates in an unfolded state. Nature 2010, 467, 868-871.

16. Groll, M.; Bajorek, M.; Kohler, A.; Moroder, L.; Rubin, D.M.; Huber, R.; Glickman, M.H.; Finley, D. A gated channel into the proteasome core particle. Nat. Struct. Biol. 2000, 7, 1062-1067.

17. Wenzel, T.; Baumeister, W. Conformational constraints in protein degradation by the $20 \mathrm{~S}$ proteasome. Nat. Struct. Biol. 1995, 2, 199-204.

18. Religa, T.L.; Sprangers, R.; Kay, L.E. Dynamic regulation of archaeal proteasome gate opening as studied by TROSY NMR. Science 2010, 328, 98-102. 
19. Latham, M.P.; Sekhar, A.; Kay, L.E. Understanding the mechanism of proteasome $20 \mathrm{~S}$ core particle gating. Proc. Natl. Acad. Sci. USA 2014, 111, 5532-5537.

20. Groll, M.; Ditzel, L.; Lowe, J.; Stock, D.; Bochtler, M.; Bartunik, H.D.; Huber, R. Structure of 20S proteasome from yeast at 2.4 A resolution. Nature 1997, 386, 463-471.

21. Borissenko, L.; Groll, M. 20S proteasome and its inhibitors: Crystallographic knowledge for drug development. Chem. Rev. 2007, 107, 687-717.

22. Tanaka, K. The proteasome: Overview of structure and functions. Proc. Jpn. Acad. Ser. B Phys. Biol. Sci. 2009, 85, 12-36.

23. Huber, E.M.; Basler, M.; Schwab, R.; Heinemeyer, W.; Kirk, C.J.; Groettrup, M.; Groll, M. Immuno- and constitutive proteasome crystal structures reveal differences in substrate and inhibitor specificity. Cell 2012, 148, 727-738.

24. Samanovic, M.I.; Li, H.; Darwin, K.H. The pup-proteasome system of mycobacterium tuberculosis. Subcell. Biochem. 2013, 66, 267-295.

25. Pearce, M.J.; Mintseris, J.; Ferreyra, J.; Gygi, S.P.; Darwin, K.H. Ubiquitin-like protein involved in the proteasome pathway of mycobacterium tuberculosis. Science 2008, 322, 1104-1107.

26. Humbard, M.A.; Miranda, H.V.; Lim, J.M.; Krause, D.J.; Pritz, J.R.; Zhou, G.; Chen, S.; Wells, L.; Maupin-Furlow, J.A. Ubiquitin-like small archaeal modifier proteins (SAMPs) in Haloferax volcanii. Nature 2010, 463, 54-60.

27. Miranda, H.V.; Nembhard, N.; Su, D.; Hepowit, N.; Krause, D.J.; Pritz, J.R.; Phillips, C.; Soll, D.; Maupin-Furlow, J.A. E1- and ubiquitin-like proteins provide a direct link between protein conjugation and sulfur transfer in archaea. Proc. Natl. Acad. Sci. USA 2011, 108, 4417-4422.

28. Hepowit, N.L.; Uthandi, S.; Miranda, H.V.; Toniutti, M.; Prunetti, L.; Olivarez, O.; de Vera, I.M.; Fanucci, G.E.; Chen, S.; Maupin-Furlow, J.A. Archaeal JAB1/MPN/MOV34 metalloenzyme (HvJAMM1) cleaves ubiquitin-like small archaeal modifier proteins (SAMPs) from protein-conjugates. Mol. Microbiol. 2012, 86, 971-987.

29. Cope, G.A.; Suh, G.S.; Aravind, L.; Schwarz, S.E.; Zipursky, S.L.; Koonin, E.V.; Deshaies, R.J. Role of predicted metalloprotease motif of Jab1/Csn5 in cleavage of Nedd8 from Cul1. Science 2002, 298, 608-611.

30. Benaroudj, N.; Goldberg, A.L. Pan, the proteasome-activating nucleotidase from archaebacteria, is a protein-unfolding molecular chaperone. Nat. Cell Biol. 2000, 2, 833-839.

31. Smith, D.M.; Kafri, G.; Cheng, Y.; Ng, D.; Walz, T.; Goldberg, A.L. ATP binding to pan or the 26S ATPases causes association with the $20 \mathrm{~S}$ proteasome, gate opening, and translocation of unfolded proteins. Mol. Cell 2005, 20, 687-698.

32. Djuranovic, S.; Hartmann, M.D.; Habeck, M.; Ursinus, A.; Zwickl, P.; Martin, J.; Lupas, A.N.; Zeth, K. Structure and activity of the N-terminal substrate recognition domains in proteasomal ATPases. Mol. Cell 2009, 34, 580-590.

33. Zhang, F.; Hu, M.; Tian, G.; Zhang, P.; Finley, D.; Jeffrey, P.D.; Shi, Y. Structural insights into the regulatory particle of the proteasome from Methanocaldococcus jannaschii. Mol. Cell 2009, 34, 473-484.

34. Smith, D.M.; Chang, S.C.; Park, S.; Finley, D.; Cheng, Y.; Goldberg, A.L. Docking of the proteasomal ATPases' carboxyl termini in the 20S proteasome's alpha ring opens the gate for substrate entry. Mol. Cell 2007, 27, 731-744. 
35. Rabl, J.; Smith, D.M.; Yu, Y.; Chang, S.C.; Goldberg, A.L.; Cheng, Y. Mechanism of gate opening in the 20S proteasome by the proteasomal ATPases. Mol. Cell 2008, 30, 360-368.

36. Stadtmueller, B.M.; Ferrell, K.; Whitby, F.G.; Heroux, A.; Robinson, H.; Myszka, D.G.; Hill, C.P. Structural models for interactions between the $20 \mathrm{~S}$ proteasome and its PAN/19s activators. J. Biol. Chem. 2010, 285, 13-17.

37. Yu, Y.; Smith, D.M.; Kim, H.M.; Rodriguez, V.; Goldberg, A.L.; Cheng, Y. Interactions of PAN's C-termini with archaeal 20S proteasome and implications for the eukaryotic proteasome-ATPase interactions. EMBO J. 2010, 29, 692-702.

38. Beck, F.; Unverdorben, P.; Bohn, S.; Schweitzer, A.; Pfeifer, G.; Sakata, E.; Nickell, S.; Plitzko, J.M.; Villa, E.; Baumeister, W.; et al. Near-atomic resolution structural model of the yeast 26S proteasome. Proc. Natl. Acad. Sci. USA 2012, 109, 14870-14875.

39. Lander, G.C.; Estrin, E.; Matyskiela, M.E.; Bashore, C.; Nogales, E.; Martin, A. Complete subunit architecture of the proteasome regulatory particle. Nature 2012, 482, 186-191.

40. Lasker, K.; Förster, F.; Bohn, S.; Walzthoeni, T.; Villa, E.; Unverdorben, P.; Beck, F.; Aebersold, R.; Sali, A.; Baumeister, W. Molecular architecture of the $26 \mathrm{~S}$ proteasome holocomplex determined by an integrative approach. Proc. Natl. Acad. Sci. USA 2012, 109, 1380-1387.

41. Tian, G.; Park, S.; Lee, M.J.; Huck, B.; McAllister, F.; Hill, C.P.; Gygi, S.P.; Finley, D. An asymmetric interface between the regulatory and core particles of the proteasome. Nat. Struct. Mol. Biol. 2011, 18, 1259-1267.

42. Ruepp, A.; Graml, W.; Santos-Martinez, M.L.; Koretke, K.K.; Volker, C.; Mewes, H.W.; Frishman, D.; Stocker, S.; Lupas, A.N.; Baumeister, W. The genome sequence of the thermoacidophilic scavenger Thermoplasma acidophilum. Nature 2000, 407, 508-513.

43. Pamnani, V.; Tamura, T.; Lupas, A.; Peters, J.; Cejka, Z.; Ashraf, W.; Baumeister, W. Cloning, sequencing and expression of VAT, a CDC48/p97 ATPase homologue from the archaeon Thermoplasma acidophilum. FEBS Lett. 1997, 404, 263-268.

44. Djuranovic, S.; Rockel, B.; Lupas, A.N.; Martin, J. Characterization of AMA, a new AAA protein from Archaeoglobus and methanogenic archaea. J. Struct. Biol. 2006, 156, 130-138.

45. Barthelme, D.; Sauer, R.T. Identification of the Cdc $48 * 20$ S proteasome as an ancient AAA+ proteolytic machine. Science 2012, 337, 843-846.

46. Forouzan, D.; Ammelburg, M.; Hobel, C.F.; Stroh, L.J.; Sessler, N.; Martin, J.; Lupas, A.N. The archaeal proteasome is regulated by a network of AAA ATPases. J. Biol. Chem. 2012, 287, 39254-39262.

47. Barthelme, D.; Chen, J.Z.; Grabenstatter, J.; Baker, T.A.; Sauer, R.T. Architecture and assembly of the archaeal Cdc48*20S proteasome. Proc. Natl. Acad. Sci. USA 2014, doi:10.1073/pnas.1404823111.

48. Glickman, M.H.; Rubin, D.M.; Coux, O.; Wefes, I.; Pfeifer, G.; Cjeka, Z.; Baumeister, W.; Fried, V.A.; Finley, D. A subcomplex of the proteasome regulatory particle required for ubiquitin-conjugate degradation and related to the Cop9-signalosome and EIF3. Cell 1998, 94, 615-623.

49. Förster, F.; Lasker, K.; Beck, F.; Nickell, S.; Sali, A.; Baumeister, W. An atomic model AAA-ATPase/20S core particle sub-complex of the 26S proteasome. Biochem. Biophys. Res. Commun. 2009, 388, 228-233. 
50. Tomko, R.J., Jr.; Funakoshi, M.; Schneider, K.; Wang, J.; Hochstrasser, M. Heterohexameric ring arrangement of the eukaryotic proteasomal ATPases: Implications for proteasome structure and assembly. Mol. Cell 2010, 38, 393-403.

51. Bohn, S.; Beck, F.; Sakata, E.; Walzthoeni, T.; Beck, M.; Aebersold, R.; Förster, F.; Baumeister, W.; Nickell, S. Structure of the 26S proteasome from schizosaccharomyces pombe at subnanometer resolution. Proc. Natl. Acad. Sci. USA 2010, 107, 20992-20997.

52. Unverdorben, P.; Beck, F.; Sledz, P.; Schweitzer, A.; Pfeifer, G.; Plitzko, J.M.; Baumeister, W.; Förster, F. Deep classification of a large cryo-EM dataset defines the conformational landscape of the 26S proteasome. Proc. Natl. Acad. Sci. USA 2014, 111, 5544-5549.

53. Sakata, E.; Bohn, S.; Mihalache, O.; Kiss, P.; Beck, F.; Nagy, I.; Nickell, S.; Tanaka, K.; Saeki, Y.; Förster, F.; et al. Localization of the proteasomal ubiquitin receptors Rpn10 and Rpn13 by electron cryomicroscopy. Proc. Natl. Acad. Sci. USA 2012, 109, 1479-1484.

54. Pathare, G.R.; Nagy, I.; Bohn, S.; Unverdorben, P.; Hubert, A.; Korner, R.; Nickell, S.; Lasker, K.; Sali, A.; Tamura, T.; et al. The proteasomal subunit Rpn6 is a molecular clamp holding the core and regulatory subcomplexes together. Proc. Natl. Acad. Sci. USA 2012, 109, 149-154.

55. Bohn, S.; Sakata, E.; Beck, F.; Pathare, G.R.; Schnitger, J.; Nagy, I.; Baumeister, W.; Förster, F. Localization of the regulatory particle subunit Sem1 in the $26 \mathrm{~S}$ proteasome. Biochem. Biophys. Res. Commun. 2013, 435, 250-254.

56. Tomko, R.J., Jr.; Hochstrasser, M. The intrinsically disordered Sem1 protein functions as a molecular tether during proteasome lid biogenesis. Mol. Cell 2014, 53, 433-443.

57. Estrin, E.; Lopez-Blanco, J.R.; Chacon, P.; Martin, A. Formation of an intricate helical bundle dictates the assembly of the 26S proteasome lid. Structure 2013, 21, 1624-1635.

58. Pathare, G.R.; Nagy, I.; Sledz, P.; Anderson, D.J.; Zhou, H.J.; Pardon, E.; Steyaert, J.; Forster, F.; Bracher, A.; Baumeister, W. Crystal structure of the proteasomal deubiquitylation module Rpn8-Rpn11. Proc. Natl. Acad. Sci. USA 2014, 111, 2984-2989.

59. Worden, E.J.; Padovani, C.; Martin, A. Structure of the Rpn11-Rpn8 dimer reveals mechanisms of substrate deubiquitination during proteasomal degradation. Nat. Struct. Mol. Biol. 2014, 21, 220-227.

60. Yao, T.; Cohen, R.E. A cryptic protease couples deubiquitination and degradation by the proteasome. Nature 2002, 419, 403-407.

61. Verma, R.; Aravind, L.; Oania, R.; McDonald, W.H.; Yates, J.R., 3rd; Koonin, E.V.; Deshaies, R.J. Role of Rpn11 metalloprotease in deubiquitination and degradation by the $26 \mathrm{~S}$ proteasome. Science 2002, 298, 611-615.

62. Förster, F.; Unverdorben, P.; Sledz, P.; Baumeister, W. Unveiling the long-held secrets of the 26S proteasome. Structure 2013, 21, 1551-1562.

63. Lander, G.C.; Martin, A.; Nogales, E. The proteasome under the microscope: The regulatory particle in focus. Curr. Opin. Struct. Biol. 2013, 23, 243-251.

64. Da Fonseca, P.C.; He, J.; Morris, E.P. Molecular model of the human 26S proteasome. Mol. Cell 2012, 46, 54-66.

65. Arai, S.; Saijo, S.; Suzuki, K.; Mizutani, K.; Kakinuma, Y.; Ishizuka-Katsura, Y.; Ohsawa, N.; Terada, T.; Shirouzu, M.; Yokoyama, S.; et al. Rotation mechanism of enterococcus hirae V1-ATPase based on asymmetric crystal structures. Nature 2013, 493, 703-707. 
66. Itsathitphaisarn, O.; Wing, R.A.; Eliason, W.K.; Wang, J.; Steitz, T.A. The hexameric helicase DnaB adopts a nonplanar conformation during translocation. Cell 2012, 151, 267-277.

67. Thomsen, N.D.; Berger, J.M. Running in reverse: The structural basis for translocation polarity in hexameric helicases. Cell 2009, 139, 523-534.

68. Sledz, P.; Unverdorben, P.; Beck, F.; Pfeifer, G.; Schweitzer, A.; Förster, F.; Baumeister, W. Structure of the $26 \mathrm{~S}$ proteasome with ATP-gammas bound provides insights into the mechanism of nucleotide-dependent substrate translocation. Proc. Natl. Acad. Sci. USA 2013, 110, 7264-7269.

69. Matyskiela, M.E.; Lander, G.C.; Martin, A. Conformational switching of the 26S proteasome enables substrate degradation. Nat. Struct. Mol. Biol. 2013, 20, 781-788.

70. Lee, M.J.; Lee, B.H.; Hanna, J.; King, R.W.; Finley, D. Trimming of ubiquitin chains by proteasome-associated deubiquitinating enzymes. Mol. Cell. Proteomics 2011, doi:10.1074/mcp.R110.003871.

71. Prakash, S.; Inobe, T.; Hatch, A.J.; Matouschek, A. Substrate selection by the proteasome during degradation of protein complexes. Nat. Chem. Biol. 2009, 5, 29-36.

72. Inobe, T.; Fishbain, S.; Prakash, S.; Matouschek, A. Defining the geometry of the two-component proteasome degron. Nat. Chem. Biol. 2011, 7, 161-167.

73. Peth, A.; Uchiki, T.; Goldberg, A.L. ATP-dependent steps in the binding of ubiquitin conjugates to the 26S proteasome that commit to degradation. Mol. Cell 2010, 40, 671-681.

74. Nyquist, K.; Martin, A. Marching to the beat of the ring: Polypeptide translocation by AAA+ proteases. Trends Biochem. Sci. 2013, 39, 53-60.

75. Sen, M.; Maillard, R.A.; Nyquist, K.; Rodriguez-Aliaga, P.; Presse, S.; Martin, A.; Bustamante, C. The ClpXP protease unfolds substrates using a constant rate of pulling but different gears. Cell 2013, 155, 636-646.

76. Wang, X.; Huang, L. Identifying dynamic interactors of protein complexes by quantitative mass spectrometry. Mol. Cell. Proteomics 2008, 7, 46-57.

77. Jacobson, A.D.; Macfadden, A.; Wu, Z.; Peng, J.; Liu, C.W. Autoregulation of the 26S proteasome by in situ ubiquitination. Mol. Biol. Cell 2014, doi:10.1091/mbc.E13-10-0585.

78. Wilkinson, C.R.; Seeger, M.; Hartmann-Petersen, R.; Stone, M.; Wallace, M.; Semple, C.; Gordon, C. Proteins containing the Uba domain are able to bind to multi-ubiquitin chains. Nat. Cell Biol. 2001, 3, 939-943.

79. Bertolaet, B.L.; Clarke, D.J.; Wolff, M.; Watson, M.H.; Henze, M.; Divita, G.; Reed, S.I. Uba domains of DNA damage-inducible proteins interact with ubiquitin. Nat. Struct. Biol. 2001, 8, 417-422.

80. Verma, R.; Oania, R.; Graumann, J.; Deshaies, R.J. Multiubiquitin chain receptors define a layer of substrate selectivity in the ubiquitin-proteasome system. Cell 2004, 118, 99-110.

81. Gomez, T.A.; Kolawa, N.; Gee, M.; Sweredoski, M.J.; Deshaies, R.J. Identification of a functional docking site in the Rpn1 LRR domain for the UBA-UBL domain protein Ddil. BMC Biol. 2011, doi:10.1186/1741-7007-9-33.

82. Schmidt, M.; Hanna, J.; Elsasser, S.; Finley, D. Proteasome-associated proteins: Regulation of a proteolytic machine. Biol. Chem. 2005, 386, 725-737. 
83. Leggett, D.S.; Hanna, J.; Borodovsky, A.; Crosas, B.; Schmidt, M.; Baker, R.T.; Walz, T.; Ploegh, H.; Finley, D. Multiple associated proteins regulate proteasome structure and function. Mol. Cell 2002, 10, 495-507.

84. Inobe, T.; Matouschek, A. Paradigms of protein degradation by the proteasome. Curr. Opin. Struct. Biol. 2014, 24, 156-164.

85. Rosenzweig, R.; Bronner, V.; Zhang, D.; Fushman, D.; Glickman, M.H. Rpn1 and Rpn2 coordinate ubiquitin processing factors at the proteasome. J. Biol. Chem. 2012, 287, 14659-14671.

86. Elsasser, S.; Gali, R.R.; Schwickart, M.; Larsen, C.N.; Leggett, D.S.; Muller, B.; Feng, M.T.; Tubing, F.; Dittmar, G.A.; Finley, D. Proteasome subunit Rpn1 binds ubiquitin-like protein domains. Nat. Cell Biol. 2002, 4, 725-730.

87. Saeki, Y.; Sone, T.; Toh-e, A.; Yokosawa, H. Identification of ubiquitin-like protein-binding subunits of the 26S proteasome. Biochem. Biophys. Res. Commun. 2002, 296, 813-819.

88. Hiyama, H.; Yokoi, M.; Masutani, C.; Sugasawa, K.; Maekawa, T.; Tanaka, K.; Hoeijmakers, J.H.; Hanaoka, F. Interaction of hHR23 with S5a. The ubiquitin-like domain of hHR23 mediates interaction with S5a subunit of 26S proteasome. J. Biol. Chem. 1999, 274, 28019-28025.

89. Walters, K.J.; Kleijnen, M.F.; Goh, A.M.; Wagner, G.; Howley, P.M. Structural studies of the interaction between ubiquitin family proteins and proteasome subunit S5a. Biochemistry 2002, 41, 1767-1777.

90. Peth, A.; Besche, H.C.; Goldberg, A.L. Ubiquitinated proteins activate the proteasome by binding to Usp14/Ubp6, which causes 20S gate opening. Mol. Cell 2009, 36, 794-804.

91. Hanna, J.; Hathaway, N.A.; Tone, Y.; Crosas, B.; Elsasser, S.; Kirkpatrick, D.S.; Leggett, D.S.; Gygi, S.P.; King, R.W.; Finley, D. Deubiquitinating enzyme Ubp6 functions noncatalytically to delay proteasomal degradation. Cell 2006, 127, 99-111.

92. Chen, X.; Lee, B.H.; Finley, D.; Walters, K.J. Structure of proteasome ubiquitin receptor hRpn13 and its activation by the scaffolding protein Hrpn2. Mol. Cell 2010, 38, 404-415.

93. Lam, Y.A.; Xu, W.; DeMartino, G.N.; Cohen, R.E. Editing of ubiquitin conjugates by an isopeptidase in the 26S proteasome. Nature 1997, 385, 737-740.

94. Holzl, H.; Kapelari, B.; Kellermann, J.; Seemuller, E.; Sumegi, M.; Udvardy, A.; Medalia, O.; Sperling, J.; Muller, S.A.; Engel, A.; et al. The regulatory complex of drosophila melanogaster 26S proteasomes. Subunit composition and localization of a deubiquitylating enzyme. J. Cell Biol. 2000, 150, 119-130.

95. Husnjak, K.; Elsasser, S.; Zhang, N.; Chen, X.; Randles, L.; Shi, Y.; Hofmann, K.; Walters, K.J.; Finley, D.; Dikic, I. Proteasome subunit Rpn13 is a novel ubiquitin receptor. Nature 2008, 453, 481-488.

96. Qiu, X.B.; Ouyang, S.Y.; Li, C.J.; Miao, S.; Wang, L.; Goldberg, A.L. hRpn13/ADRM1/GP110 is a novel proteasome subunit that binds the deubiquitinating enzyme, UCH37. EMBO J. 2006, $25,5742-5753$.

97. Hamazaki, J.; Iemura, S.; Natsume, T.; Yashiroda, H.; Tanaka, K.; Murata, S. A novel proteasome interacting protein recruits the deubiquitinating enzyme $\mathrm{UCH} 37$ to $26 \mathrm{~S}$ proteasomes. EMBO J. 2006, 25, 4524-4536. 
98. Crosas, B.; Hanna, J.; Kirkpatrick, D.S.; Zhang, D.P.; Tone, Y.; Hathaway, N.A.; Buecker, C.; Leggett, D.S.; Schmidt, M.; King, R.W.; et al. Ubiquitin chains are remodeled at the proteasome by opposing ubiquitin ligase and deubiquitinating activities. Cell 2006, 127, 1401-1413.

99. Jarosch, E.; Taxis, C.; Volkwein, C.; Bordallo, J.; Finley, D.; Wolf, D.H.; Sommer, T. Protein dislocation from the ER requires polyubiquitination and the AAA-ATPase Cdc48. Nat. Cell Biol. 2002, 4, 134-139.

100. Ye, Y.; Meyer, H.H.; Rapoport, T.A. The AAA ATPase Cdc48/p97 and its partners transport proteins from the ER into the cytosol. Nature 2001, 414, 652-656.

101. Rabinovich, E.; Kerem, A.; Frohlich, K.U.; Diamant, N.; Bar-Nun, S. AAA-ATPase p97/Cdc48p, a cytosolic chaperone required for endoplasmic reticulum-associated protein degradation. Mol. Cell. Biol. 2002, 22, 626-634.

102. Xu, S.; Peng, G.; Wang, Y.; Fang, S.; Karbowski, M. The AAA-ATPase p97 is essential for outer mitochondrial membrane protein turnover. Mol. Biol. Cell 2011, 22, 291-300.

103. Verma, R.; Oania, R.S.; Kolawa, N.J.; Deshaies, R.J. Cdc48/p97 promotes degradation of aberrant nascent polypeptides bound to the ribosome. eLife 2013, 2, e00308.

104. Dantuma, N.P.; Hoppe, T. Growing sphere of influence: Cdc48/p97 orchestrates ubiquitin-dependent extraction from chromatin. Trends Cell Biol. 2012, 22, 483-491.

105. Johnson, E.S.; Ma, P.C.; Ota, I.M.; Varshavsky, A. A proteolytic pathway that recognizes ubiquitin as a degradation signal. J. Biol. Chem. 1995, 270, 17442-17456.

106. Lee, R.J.; Liu, C.W.; Harty, C.; McCracken, A.A.; Latterich, M.; Romisch, K.; DeMartino, G.N.; Thomas, P.J.; Brodsky, J.L. Uncoupling retro-translocation and degradation in the ER-associated degradation of a soluble protein. EMBO J. 2004, 23, 2206-2215.

107. Wahlman, J.; DeMartino, G.N.; Skach, W.R.; Bulleid, N.J.; Brodsky, J.L.; Johnson, A.E. Real-time fluorescence detection of ERAD substrate retrotranslocation in a mammalian in vitro system. Cell 2007, 129, 943-955.

108. Lipson, C.; Alalouf, G.; Bajorek, M.; Rabinovich, E.; Atir-Lande, A.; Glickman, M.; Bar-Nun, S. A proteasomal ATPase contributes to dislocation of endoplasmic reticulum-associated degradation (ERAD) substrates. J. Biol. Chem. 2008, 283, 7166-7175.

109. Braun, S.; Matuschewski, K.; Rape, M.; Thoms, S.; Jentsch, S. Role of the ubiquitin-selective $\mathrm{Cdc} 48^{\mathrm{UFD} 1 / \mathrm{NP} 14}$ chaperone (segregase) in ERAD of OLE1 and other substrates. EMBO J. 2002, $21,615-621$.

110. Hitchcock, A.L.; Krebber, H.; Frietze, S.; Lin, A.; Latterich, M.; Silver, P.A. The conserved npl4 protein complex mediates proteasome-dependent membrane-bound transcription factor activation. Mol. Biol. Cell 2001, 12, 3226-3241.

111. Rape, M.; Hoppe, T.; Gorr, I.; Kalocay, M.; Richly, H.; Jentsch, S. Mobilization of processed, membrane-tethered Spt 23 transcription factor by $\mathrm{Cdc} 48^{\mathrm{UFD1} / \mathrm{NPL} 4}$, a ubiquitin-selective chaperone. Cell 2001, 107, 667-677.

112. Richly, H.; Rape, M.; Braun, S.; Rumpf, S.; Hoege, C.; Jentsch, S. A series of ubiquitin binding factors connects Cdc48/p97 to substrate multiubiquitylation and proteasomal targeting. Cell 2005, 120, 73-84.

113. Rumpf, S.; Jentsch, S. Functional division of substrate processing cofactors of the ubiquitin-selective Cdc48 chaperone. Mol. Cell 2006, 21, 261-269. 
114. Hanzelmann, P.; Stingele, J.; Hofmann, K.; Schindelin, H.; Raasi, S. The yeast E4 ubiquitin ligase Ufd2 interacts with the ubiquitin-like domains of Rad23 and Dsk2 via a novel and distinct ubiquitin-like binding domain. J. Biol. Chem. 2010, 285, 20390-20398.

115. Jentsch, S.; Rumpf, S. Cdc48 (p97): A "molecular gearbox" in the ubiquitin pathway? Trends Biochem. Sci. 2007, 32, 6-11.

116. DeLaBarre, B.; Brunger, A.T. Complete structure of $\mathrm{p} 97 /$ valosin-containing protein reveals communication between nucleotide domains. Nat. Struct. Biol. 2003, 10, 856-863.

117. Davies, J.M.; Brunger, A.T.; Weis, W.I. Improved structures of full-length p97, an AAA ATPase: Implications for mechanisms of nucleotide-dependent conformational change. Structure 2008, 16, 715-726.

118. Rothballer, A.; Tzvetkov, N.; Zwickl, P. Mutations in p97/VCP induce unfolding activity. FEBS Lett. 2007, 581, 1197-1201.

119. Barthelme, D.; Sauer, R.T. Bipartite determinants mediate an evolutionarily conserved interaction between Cdc48 and the 20S peptidase. Proc. Natl. Acad. Sci. USA 2013, 110, 3327-3332.

120. Davies, J.M.; Tsuruta, H.; May, A.P.; Weis, W.I. Conformational changes of p97 during nucleotide hydrolysis determined by small-angle X-ray scattering. Structure 2005, 13, 183-195.

121. Briggs, L.C.; Baldwin, G.S.; Miyata, N.; Kondo, H.; Zhang, X.; Freemont, P.S. Analysis of nucleotide binding to $\mathrm{p} 97$ reveals the properties of a tandem AAA hexameric ATPase. J. Biol. Chem. 2008, 283, 13745-13752.

122. Song, C.; Wang, Q.; Li, C.C. ATPase activity of p97-valosin-containing protein (VCP). D2 mediates the major enzyme activity, and D1 contributes to the heat-induced activity. J. Biol. Chem. 2003, 278, 3648-3655.

123. Smith, D.M.; Fraga, H.; Reis, C.; Kafri, G.; Goldberg, A.L. ATP binds to proteasomal ATPases in pairs with distinct functional effects, implying an ordered reaction cycle. Cell 2011, 144, 526-538.

124. Noi, K.; Yamamoto, D.; Nishikori, S.; Arita-Morioka, K.; Kato, T.; Ando, T.; Ogura, T. High-speed atomic force microscopic observation of ATP-dependent rotation of the AAA+ chaperone p97. Structure 2013, 21, 1992-2002.

125. Yeung, H.O.; Forster, A.; Bebeacua, C.; Niwa, H.; Ewens, C.; McKeown, C.; Zhang, X.; Freemont, P.S. Inter-ring rotations of AAA ATPase p97 revealed by electron cryomicroscopy. Open Biol. 2014, doi:10.1098/rsob.130142.

126. Rouiller, I.; DeLaBarre, B.; May, A.P.; Weis, W.I.; Brunger, A.T.; Milligan, R.A.; Wilson-Kubalek, E.M. Conformational changes of the multifunction p97 AAA ATPase during its ATPase cycle. Nat. Struct. Biol. 2002, 9, 950-957.

127. Meyer, H.H.; Kondo, H.; Warren, G. The p47 co-factor regulates the ATPase activity of the membrane fusion protein, p97. FEBS Lett. 1998, 437, 255-257.

128. Coles, M.; Diercks, T.; Liermann, J.; Groger, A.; Rockel, B.; Baumeister, W.; Koretke, K.K.; Lupas, A.; Peters, J.; Kessler, H. The solution structure of VAT-N reveals a "missing link" in the evolution of complex enzymes from a simple betaalphabetabeta element. Curr. Biol. 1999, 9 , 1158-1168.

129. Dreveny, I.; Kondo, H.; Uchiyama, K.; Shaw, A.; Zhang, X.; Freemont, P.S. Structural basis of the interaction between the AAA ATPase p97/VCP and its adaptor protein p47. EMBO J. 2004, 23, 1030-1039. 
130. Schuberth, C.; Buchberger, A. Ubx domain proteins: Major regulators of the AAA ATPase Cdc48/p97. Cell. Mol. Life Sci. 2008, 65, 2360-2371.

131. Golbik, R.; Lupas, A.N.; Koretke, K.K.; Baumeister, W.; Peters, J. The Janus face of the archaeal Cdc48/p97 homologue VAT: Protein folding vs. unfolding. Biol. Chem. 1999, 380, 1049-1062.

132. Park, S.; Isaacson, R.; Kim, H.T.; Silver, P.A.; Wagner, G. Ufd1 exhibits the AAA-ATPase fold with two distinct ubiquitin interaction sites. Structure 2005, 13, 995-1005.

133. Bruderer, R.M.; Brasseur, C.; Meyer, H.H. The AAA ATPase p97/VCP interacts with its alternative co-factors, Ufd1-Np14 and p47, through a common bipartite binding mechanism. J. Biol. Chem. 2004, 279, 49609-49616.

134. Isaacson, R.L.; Pye, V.E.; Simpson, P.; Meyer, H.H.; Zhang, X.; Freemont, P.S.; Matthews, S. Detailed structural insights into the p97-Np14-Ufd1 interface. J. Biol. Chem. 2007, 282, 21361-21369.

135. Wang, B.; Alam, S.L.; Meyer, H.H.; Payne, M.; Stemmler, T.L.; Davis, D.R.; Sundquist, W.I. Structure and ubiquitin interactions of the conserved zinc finger domain of Np14. J. Biol. Chem. 2003, 278, 20225-20234.

136. Bebeacua, C.; Forster, A.; McKeown, C.; Meyer, H.H.; Zhang, X.; Freemont, P.S. Distinct conformations of the protein complex p97-Ufd1-Npl4 revealed by electron cryomicroscopy. Proc. Natl. Acad. Sci. USA 2012, 109, 1098-1103.

137. Bohm, S.; Lamberti, G.; Fernandez-Saiz, V.; Stapf, C.; Buchberger, A. Cellular functions of Ufd 2 and Ufd 3 in proteasomal protein degradation depend on Cdc48 binding. Mol. Cell. Biol. 2011, 31, 1528-1539.

138. Tu, D.; Li, W.; Ye, Y.; Brunger, A.T. Structure and function of the yeast U-box-containing ubiquitin ligase Ufd2p. Proc. Natl. Acad. Sci. USA 2007, 104, 15599-15606.

139. Koeg1, M.; Hoppe, T.; Schlenker, S.; Ulrich, H.D.; Mayer, T.U.; Jentsch, S. A novel ubiquitination factor, E4, is involved in multiubiquitin chain assembly. Cell 1999, 96, 635-644.

140. Boeddrich, A.; Gaumer, S.; Haacke, A.; Tzvetkov, N.; Albrecht, M.; Evert, B.O.; Muller, E.C.; Lurz, R.; Breuer, P.; Schugardt, N.; et al. An arginine/lysine-rich motif is crucial for $\mathrm{VCP} / \mathrm{p} 97-$ mediated modulation of Ataxin-3 fibrillogenesis. EMBO J. 2006, 25, 1547-1558.

141. Qiu, L.; Pashkova, N.; Walker, J.R.; Winistorfer, S.; Allali-Hassani, A.; Akutsu, M.; Piper, R.; Dhe-Paganon, S. Structure and function of the Plaa/Ufd3-p97/Cdc48 complex. J. Biol. Chem. 2010, 285, 365-372.

142. Zhao, G.; Li, G.; Schindelin, H.; Lennarz, W.J. An armadillo motif in Ufd3 interacts with Cdc48 and is involved in ubiquitin homeostasis and protein degradation. Proc. Natl. Acad. Sci. USA 2009, 106, 16197-16202.

143. Kim, S.J.; Cho, J.H.; Song, E.J.; Kim, S.J.; Kim, H.M.; Lee, K.E.; Suh, S.W.; Kim, E.E. Structural basis for ovarian tumor domain-containing protein 1 (OTU1) binding to p97/valosincontaining protein (VCP). J. Biol. Chem. 2014, 289, 12264-12274.

(C) 2014 by the authors; licensee MDPI, Basel, Switzerland. This article is an open access article distributed under the terms and conditions of the Creative Commons Attribution license (http://creativecommons.org/licenses/by/3.0/). 